\title{
Do processo de formação da legislação cooperativa brasileira à atualidade das cooperativas agrícolas e de consumo: a nova estrutura do cooperativismo brasileiro
}

From the formation process of brazilian cooperative cooperatives to the current agricultural and consumption cooperatives: the new structure of brazilian cooperativism

\author{
Victória Corrêa Lima de Miranda ${ }^{1}$ \\ José Eduardo de Miranda²
}

UniMB

Sumário: I. Introdução; II. O processo histórico da legislação cooperativa brasileira; III. O Cooperativismo no plano constitucional; IV. Peculiaridades das Cooperativas Agropecuárias; V. Particularidades das Cooperativas de Consumo; VI. A nova estrutura do Cooperativismo brasileiro; VII. Palavras derradeiras; Referências.

Resumo: O presente trabalho aborda o processo histórico de formação da legislação cooperativa brasileira, perpassando pela expressão do Cooperativismo no plano da Constituição da República Federativa do Brasil, de 1988. Assim mesmo, e tendo em vista sua importância para o desenvolvimento socioeconômico da sociedade brasileira, retrata as principais características dos ramos agropecuário e de consumo. Finalmente, e levando em consideração a atuação da Organização das Cooperativas Brasileiras, apresenta a atual estruturação dos ramos cooperativos.

Palavras-chave: Legislação cooperativa brasileira; Ramos do Cooperativismo no Brasil; Cooperativas Agrícolas e de Consumo.

Abstract: The present work addresses the historical process of formation of Brazilian cooperative legislation, going through the expression of Cooperativism in the plan of the Constitution of the Federative Republic of Brazil, of

1 Graduada em Direito pelo UniMB; Pós-graduanda em Direito Processual Civil pela Damásio de Jesus; E-mail: mirandavick10@yahoo.com.br

2 Doutor em Direito cum laude academica; Mestre em Direito; Reitor do UniMB; Advogado Parecerista; Consultor Jurídico e Educacional; Fundador de Miranda \& Corrêa Lima. E-mail: jemiranda@mirandacorrealima.com 
1988. Likewise, and considering its importance for the socioeconomic development of Brazilian society, it portrays the main characteristics of the agricultural and consumer sectors. Finally, and taking into account the activities of the Organization of Brazilian Cooperatives, it presents the current structure of the cooperative branches.

Keywords: Brazilian cooperative legislation; Branches of Cooperativism in Brazil; Agricultural and Consumer Cooperatives. 
La primera forma de justicia elemental es la que necesitamos practicar los unos con los otros otorgándonos la consideración de seres libres.

José Maria Arizmendiarrieta ${ }^{3}$

\section{Introdução}

O Cooperativismo brasileiro desenvolveu-se, quem sabe de forma intuitiva, assentando sua trajetória sobre valores e princípios éticosmorais que orientaram práticas cooperacionistas preliminares, que sucederam a formalidade constitutiva de sociedades cooperativas. Neste sentido, em 1847, o francês Jean Maurice Faivre, convicto dos efeitos positivos da cooperação, e com o propósito de constituir uma sociedade igualitária em terras brasileiras, livre do egoísmo e da escravidão, fundou a Vila Agrícola Tereza Cristina, localizada no litoral paranaense.

A despeito desta experiência, e seguindo a tendência inaugurada pelos Probos Pioneiros de Rochdale, reputados predecessores do Cooperativismo moderno, o Brasil conheceu sua primeira sociedade cooperativa em 1887, constituída em Campinas, no estado de São Paulo, sob o nome de Cooperativa de Consumo dos Empregados da Companhia Paulista. Posteriormente, no ano de 1889, foi criada, no estado de Minas Gerais, a Cooperativa Econômica dos Funcionários Públicos de Ouro Preto.

Adiante, foram fundadas a Associação Cooperativa Telefônica de Limeira, em 1891, no estado de São Paulo, a Cooperativa Militar de Consumo do Distrito Federal, em 1894, no estado do Rio de Janeiro, e a Cooperativa de Consumo de Camaragibe, no ano de 1895, no estado de Pernambuco. Em 1902, o Padre suíço Theodre Amstad fundou, na cidade de Nova Petrópolis, no estado do Rio Grande do Sul, a Sicred Pioneira, que se encontra em atividade até os dias de hoje.

Ainda no transcurso da primeira metade do século Xx, consolidaram-se cooperativas agropecuárias, instituídas por produtores rurais e por imigrantes italianos e alemães.

Malgrado a solidez e a tenacidade das iniciativas que marcaram a evolução do Cooperativismo no Brasil, deve-se enaltecer a criação da Organização das Cooperativas Brasileiras (OCB), em 1969, e a publip. 44.

3 Arizmendiarrieta, José Maria: Pensamientos. Caja laboral Popular, Estella, 1983, 
cação da Lei 5.761, responsável pela definição da Política Nacional de Cooperativismo, e pela instituição do regime jurídico próprio das sociedades cooperativas, no ano de 1971.

O auge do Cooperativismo brasileiro ocorreu em 1988, com a promulgação da Constituição da República Federativa do Brasil, pois, na medida em que a carta política vetou a interferência estatal no processo de criação de cooperativas, determinou que o Estado tanto incentivasse o Cooperativismo, como otimizasse o adequado tratamento tributário do ato cooperativo.

Fato seguinte, tem-se que o apogeu de reconhecimento internacional do Cooperativismo brasileiro ocorre a partir de 1995, momento em que o ex-presidente da Organização das Cooperativas Brasileiras, Roberto Rodrigues, é eleito para a presidência da Aliança Cooperativa Internacional.

Por esta trilha, implementou-se, no território brasileiro, uma expressiva evolução do modelo cooperativo, o que provocou a conformação de legislações especiais, publicadas para regulamentar ramos específicos. Deste modo, e considerando-se a robustez da matéria, este artigo tem o propósito de equalizar o entendimento sobre a evolução legislativa do Cooperativismo no Brasil. Conscientes da magnitude numérica de textos legais, serão apresentadas as principais leis em matéria cooperativa que foram editadas no decorrer da história, oferecendo-se destaque aos elementos nucleares de cada uma delas. Assim mesmo, e apenas de forma ilustrativa, serão apresentadas todas as Leis estaduais, criadas pelas unidades federativas para promoverem o fomento da atividade cooperativa.

Seguidamente, far-se-á um delineamento sobre as peculiaridades das cooperativas agrícolas, assim como serão minudenciadas as particularidades das cooperativas de consumo. Por fim, apresentar-se-á a nova estrutura do Cooperativismo brasileiro, descrevendo, além da reconfiguração dos ramos de cooperativas, as razões pelas quais a Organização das Cooperativas brasileiras, a OCB decidiu empreender a reestruturação organizacional.

\section{O processo histórico da legislação cooperativa brasileira}

Muito embora o Brasil tenha conhecido experiências cooperativas baseadas no vértice de valor da cooperação pura, a legislação cooperativa passa a consolidar-se somente a partir do início do século Xx. Neste sentido, em 1903, promulga-se o Decreto 979, em 06 de janeiro, em cujo artigo 10 permitiu-se que os sindicatos organizassem caixas de 
crédito e de cooperativas de produção e de consumo. Sobre este aspecto, o referido dispositivo prescrevia que «a função dos sindicatos nos casos de organização de caixas rurais de crédito agrícola e de cooperativa de produção ou de consumo, de sociedade de seguros, assistência, etc., não implica responsabilidade direta dos mesmos nas transações, nem os bens nelas empregados ficam sujeitos ao disposto no n. 8, sendo a liquidação de tais organizações regidas pela lei comum das sociedades civis» ${ }^{4}$.

No ano de 1907, foi publicado o Decreto $1.637^{5}$, de 05 de janeiro, que nasceu com o objetivo de legitimar a criação de sindicatos profissionais e de cooperativas. Observada a especificidade do texto, destaca-se que o artigo 10 estabelecia que as sociedades cooperativas podiam ser anônimas, em nome coletivo ou em comandita, sempre regidas pela legislação reguladora de cada um desses tipos societários. O artigo 11, por sua vez, descrevia as principais características da sociedade cooperativa, quais sejam: variabilidade do capital social; não limitação do número de sócios; e inacessibilidade das quotas partes a terceiros estranhos à sociedade. Já, o artigo 13, estabelecia que as sociedades cooperativas podiam ser constituídas tanto por escritura pública, como por deliberação de assembleia dos sócios.

Em 1932, no dia 19 de dezembro, foi publicado o Decreto 22.239, com o propósito de alterar o Decreto 1.637/1907, essencialmente na parte relativa às cooperativas ${ }^{6}$. A primeira importante modificação instituída por este documento consta do artigo $1 .^{\circ}$, pela determinação do número mínimo de 07 pessoas para a constituição de uma sociedade cooperativa. Sobre as características gerais das sociedades cooperativas, o artigo $2 .^{\circ}$ dispõe que, além de serem sociedades eminentemente de pessoas, o ato constitutivo não poderia discorrer sobre questões que infringissem: a) a variabilidade do capital social, para as constituídas com capital social declarado; b) a limitação do número máximo de membros; c) a limitação do valor da quota parte de cada membro; d) a incessibilidade das quotas partes a estranhos à sociedade; e) o quórum para funcionar e deliberar a assembleia geral, fundado no número de

4 Brasil, 1903. Decreto $n .^{\circ} 979$, de 6 de janeiro de 1903. Disponível em https:// www2.camara.leg.br/legin/fed/decret/1900-1909/decreto-979-6-janeiro-1903 Acesso em 16 nov 2020.

5 Brasil, 1907. Decreto n. ${ }^{\circ}$ 1.637, de 05 de janeiro de 2907. Disponível em https://www2.camara.leg.br/legin/fed/decret/1900-1909/decreto-1637-5-janeiro-1907582195-publicacaooriginal-104950-pl.html Acesso em 17 nov 2020.

6 Brasil, 1932. Decreto . $^{\circ}$ 22.239, de 19 de dezembro de 1922. Disponível em https://www2.camara.leg.br/legin/fed/decret/1930-1939/decreto-22239-19-dezembro1932-501764-publicacaooriginal-1- . Acesso em 17 nov 2020. 
associados presentes na reunião, e não no capital social; f) a distribuição das sobras, na proporção do valor das operações realizadas pelo associado com a cooperativa, podendo-se atribuir ao capital social um juro fixo não maior do que $9 \%$ ao ano, e fixação de um dividendo de, no máximo, $12 \%$ ao ano, fixado proporcionalmente ao valor das quotas partes de capital; $g$ ) indivisibilidade do fundo de reservas, mesmo em caso de dissolução da sociedade; $h$ ) singularidade do voto nas deliberações; i) área de ação determinada. Em relação à gestão da cooperativa, o artigo 15 estabeleceu que toda a sociedade cooperativa teria sua gestão assistida e controlada por um conselho de sindicância, comissão de contas, ou conselho fiscal, compostos por três ou mais membros efetivos e suplentes, em igual número. O artigo 22 classificou as dezesseis principais categorias de sociedades cooperativas, a saber: de produção agrícola; de produção industrial; de trabalho (profissionais ou de classe); de beneficiamento de produtos; de compras em comum; de vendas em comum; de consumo; de abastecimento; de crédito; de seguros; de construção de casas populares; de editoras e de cultura intelectual; escolares; mistas; centrais; e de federações.

Os consórcios profissionais cooperativos foram criados pelo Decreto 23.6117, de 20 de dezembro de 1933, o qual foi modificado em 1934 pelo Decreto $24.647^{8}$, que instituiu o patrimônio dos consórcios profissionais cooperativos. Ato seguinte, em 1938, o Decreto $581^{9}$, de 1 de agosto, instituiu o sistema de registro, fiscalização e assistência das sociedades cooperativas.

Com o Decreto $5.893^{10}$, de 19 de outubro de 1943, criou-se a Caixa de Crédito Cooperativo, destinada ao financiamento e fomento do Cooperativismo no território nacional. A Caixa de Crédito funcionou até o ano de 1951, quando foi substituída pelo Banco Nacional de Crédito Cooperativo, o BNCC, criado por força da Lei 1.412, de 13 de agosto. De acordo com o artigo $2 .^{\circ}$, da mencionada lei, o

7 Brasil, 1933. Decreto 23.611, de 20 de dezembro de 1933. Disponível em http:// www.planalto.gov.br/ccivil_03/decreto/antigos/d23611.htm Acesso em 17 nov 2020.

8 Brasil, 1934. Decreto 24.647, de 10 de julho de 1934. Disponível em http://www. planalto.gov.br/ccivil_03/decreto/1930-1949/D24647.htm\#: :text=DECRETO\%20 N\% C 2\%BA \% 2024.647\% 2C \% 20DE \% 2010\% 20DE \% 20JULHO \% 20DE \% 20 1934.\&text $=22.239 \% 2$ C \%20de\%2019\%20de\%20dezembro,Patrim\%C3\%B4nio\%20 dos $\% 20$ Cons $\%$ C3\%B3rcios\%20Profissionais\%2DCooperativos. Acesso em 17 nov 2020.

9 Brasil, 1938. Decreto 581, de 1 de agosto de 1938. Disponível em http://www. planalto.gov.br/ccivil_03/Decreto-Lei/1937-1946/Del581.htm Acesso em 28 nov 2020.

10 Brasil, 1943. Decreto 5.893, de 19 de outubro de 1943. Disponível em http:// www.planalto.gov.br/ccivil_03/Atos/del/1943/Del05893.htm . Acesso em 17 nov 2020. 
BNCC tinha "por objeto a assistência e o amparo financeiro às cooperativas, mediante a realização de atos e operações peculiares, e observará subsidiariamente o regulamento aprovado para a Caixa de Crédito Cooperativo» ${ }^{11}$. O BNCC foi extinto em 21 de março de 1990.

$\mathrm{Na}$ esfera do Cooperativismo de crédito, em 1964, a Lei 4.595, equiparou as cooperativas de crédito às demais instituições financeiras, transferindo ao Banco Central do Brasil todas as atribuições relativas à autorização de funcionamento, e fiscalização, outrora concedidas ao Ministério da Agricultura ${ }^{12}$.

O grande salto legislativo em matéria cooperativa, no território brasileiro, operou-se no ano de 1971, através da Lei 5.764, de 16 de dezembro, publicada para definir a Política Nacional do Cooperativismo, e instituir o regime jurídico das sociedades cooperativas ${ }^{13}$. De acordo com o artigo $1 .^{\circ}$, desta lei, a Política Nacional de Cooperativismo representa «a atividade decorrente das iniciativas ligadas ao sistema cooperativo, originárias de setor público ou privado, isoladas ou coordenadas entre si, desde que reconhecido seu interesse público» ${ }^{14}$. Pelo artigo $4 .^{\circ}$, tem-se que as cooperativas «são sociedades de pessoas, com forma e natureza jurídica próprias, de natureza civil, não sujeitas à falência, constituídas para prestar serviços aos associados» ${ }^{15}$. A distinção das sociedades cooperativas, dos demais modelos societários, se dá em virtude das seguintes características:

I. Adesão voluntária, com número ilimitado de associados, salvo impossibilidade técnica de prestação de serviços;

II. Variabilidade do capital social representado por quotas-partes;

III. Limitação do número de quotas-partes do capital para cada associado, facultado, porém, o estabelecimento de critérios de proporcionalidade, se assim for mais adequado para o cumprimento dos objetivos sociais;

IV. Incessibilidade das quotas-partes do capital a terceiros, estranhos à sociedade;

$V$. Singularidade de voto, podendo as cooperativas centrais, federações e confederações de cooperativas, com exceção das que exerçam atividade de crédito, optar pelo critério da proporcionalidade;

11 Brasil, 1951. Lei 1.412. de 13 de agosto de 1951. Disponível em http://www. planalto.gov.br/ccivil_03/leis/1950-1969//1412.htm Acesso em 12 dez 2020.

12 Brasil, 1964. Lei 4.595, de 31 de dezembro. Disponível em http://www.planalto. gov.br/ccivil_03/leis/14595.htm Acesso em 17 dez 2020.

13 Brasil, 1971. Lei 5.764, de 16 de dezembro de 1971. Disponível em http://www. planalto.gov.br/ccivil_03/leis/15764.htm Acesso em 17 dez 2020.

14 Brasil, 1971.

15 Ibid. 
VI. Quórum para o funcionamento e deliberação da Assembleia Geral baseado no número de associados e não no capital;

VII. Retorno das sobras líquidas do exercício, proporcionalmente às operações realizadas pelo associado, salvo deliberação em contrário da Assembleia Geral;

VIII. Indivisibilidade dos fundos de Reserva e de Assistência Técnica Educacional e Social; cial;

IX. Neutralidade política e indiscriminação religiosa, racial e so-

X. Prestação de assistência aos associados, e, quando previsto nos estatutos, aos empregados da cooperativa;

$\mathrm{XI}$. Área de admissão de associados limitada às possibilidades de reunião, controle, operações e prestação de serviços. ${ }^{16}$

Relativamente à classificação das sociedades cooperativas, o artigo $6 .^{\circ}$ estabeleceu que são reputadas:

I. Singulares, as constituídas pelo número mínimo de 20 (vinte) pessoas físicas, sendo excepcionalmente permitida a admissão de pessoas jurídicas que tenham por objeto as mesmas ou correlatas atividades econômicas das pessoas físicas ou, ainda, aquelas sem fins lucrativos;

II. Cooperativas centrais ou federações de cooperativas, as constituídas de, no mínimo, 3 (três) singulares, podendo, excepcionalmente, admitir associados individuais;

III. Confederações de cooperativas, as constituídas, pelo menos, de 3 (três) federações de cooperativas ou cooperativas centrais, da mesma ou de diferentes modalidades. ${ }^{17}$

Buscando viabilizar a integração social dos cidadãos, em 1999 publicou-se a Lei 9.867 , de 10 de novembro, que regulamentou a criação e o funcionamento das Cooperativas Sociais, "constituídas com a finalidade de inserir as pessoas em desvantagem no mercado econômico, por meio do trabalho, fundamentam-se no interesse geral da comunidade em promover a pessoa humana e a integração social dos cidadãos, e incluem entre suas atividades: I - a organização e gestão de serviços socio sanitários e educativos; e II - o desenvolvimento de atividades agrícolas, industriais, comerciais e de serviços» ${ }^{18}$.

16 Brasil, 1971.

17 Brasil, 1971.

18 Brasil, 1999. Lei 9.867, de 10 de novembro de 1999. Disponível em http://www. planalto.gov.br/ccivil_03/leis/L9867.htm Acesso em 17 dez 2020. 
O Código Civil brasileiro, Lei 10.406, de 10 de janeiro de 2002, convergente com os preceitos da Lei 5.764/71, dispõe que a responsabilidade dos sócios: é limitada na cooperativa em que o sócio responde somente pelo valor de suas quotas e pelo prejuízo verificado nas operações sociais, guardada a proporção de sua participação nas mesmas operaçôes; e ilimitada na cooperativa em que o sócio responde solidária e ilimitadamente pelas obrigações sociais ${ }^{19}$.

Um verdadeiro marco no âmbito do Cooperativismo de Crédito foi a publicação da Lei Complementar 130, de 17 de novembro de 2009. Ademais de resguardar o vínculo das cooperativas de crédito ao Sistema Financeiro Nacional, a LC 130 definiu que «as cooperativas de crédito se destinam, precipuamente, a prover, por meio da mutualidade, a prestação de serviços financeiros a seus associados, sendo-lhes assegurado $\mathrm{o}$ acesso aos instrumentos do mercado financeiro ${ }^{20}$.

$\mathrm{Na}$ ordem das cooperativas de trabalho, a Lei 12.690, de 19 de julho de 2012, dispõe sobre sua respectiva organização e funcionamento, além de instituir o Programa Nacional de Fomento às Cooperativas de Trabalho. Sobre este aspecto, deve-se ressaltar que o parágrafo único, do artigo $1 .^{\circ}$, exclui, do alcance da Lei $12.690 / 2012$, as cooperativas de assistência à saúde na forma da legislação de saúde suplementar; as cooperativas que atuam no setor de transporte regulamentado pelo poder público e que detenham, por si ou por seus sócios, a qualquer título, os meios de trabalho; as cooperativas de profissionais liberais cujos sócios exerçam as atividades em seus próprios estabelecimentos; e as cooperativas de médicos cujos honorários sejam pagos por procedimento ${ }^{21}$.

Não obstante, deve-se advertir que o artigo $2 .^{\circ}$ considera a sociedade cooperativa de trabalho é «constituída por trabalhadores para o exercício de suas atividades laborativas ou profissionais com proveito comum, autonomia e autogestão para obterem melhor qualificação, renda, situação socioeconômica e condições gerais de trabalho ${ }^{22}$.

Verificada a peculiaridade histórico-temporal no processo de formação da legislação cooperativa no Brasil, destaca-se que existe, ainda,

19 Brasil, 2002. Lei 10.406, de 10 de janeiro. Disponível em http://www.planalto. gov.br/ccivil_03/leis/2002/L10406compilada.htm Acesso em 22 dez 2020.

20 Brasil, 2009. Lei complementar 130, de 17 de novembro de 2009. Disponível em http://www.planalto.gov.br/ccivil_03/leis/LCP/Lcp130.htm Acesso em 17 dez 2020.

21 Brasil, 2012. Lei 12.690, de 9 de julho de 2012. Disponível em http://www. planalto.gov.br/ccivil_03/_Ato2011-2014/2012/Lei/L12690.htm Acesso em 17 dez 2020.

22 Brasil, 2012. 
um remanso legislativo publicado pelo Estados, para fomentar e apoiar o Cooperativismo regional. É o caso do Acre, com a Lei 1.598, de 27 de dezembro de 2004; de Alagoas, com a Lei 6.904, de 3 de janeiro de 2008; do Amapá, com a Lei 1.131, de 25 de outubro de 2007; do Amazonas, com a PEC 04/2012; da Bahia, com a Lei 11.362, de 26 de janeiro de 2009; do Espírito Santo, com a Lei 8.257, de 17 de janeiro de 2006; de Goiás, com a Lei 15.109, de 02 de fevereiro de 2005; do Maranhão, com a Lei 9.170, de 16 de abril de 2010; do Mato Grosso, com a Lei 9.129, de 12 de maio; do Mato Grosso do Sul, com a Lei 2.830, de 12 de maio de 2004; de Minas Gerais, com a Lei 15.075, de 05 de abril de 2004; do Pará, com a Lei 7.780, de 26 de dezembro de 2013; do Paraná, com a Lei 17.142, de 04 de maio de 2012; de Pernambuco, com a Lai 15.688, de 16 de dezembro de 2015; do Piauí, com a Lei 6.852, de 12 de julho de 2016; do Rio de Janeiro, com a Lei 7.770, de 06 de novembro de 2017; do Rio Grande do Norte, com a Lei 8.553, de 03 de agosto de 2004; do Rio Grande do Sul, com as Leis 11.829, de 5 de setembro de 2002, e Lei 11.995, de 30 de outubro de 2003; de Rondônia, com a Lei 1.462, de 11 de abril de 2005; e de Santa Catarina, com a Lei 16.834, de 16 de dezembro de 2015.

\section{O cooperativismo no plano constitucional}

A vigente Constituição brasileira marca um momento histórico significativo, de resgate da democracia, de reconhecimento das liberdades, e, essencialmente, da alocação da dignidade da pessoa humana como força motriz de orientação de todo a legislação infraconstitucional no território brasileiro. Por este caminho, afirma-se, sem temor ao equívoco, que a Constituição da República Federativa do Brasil, promulgada em 1988, enalteceu a importância do Cooperativismo, acentuando sua relevância para o desenvolvimento socioeconômico da nação brasileira.

Não bastasse, «fundamentos como cidadania, dignidade da pessoa humana, valor social do trabalho, livre iniciativa e pluralismo político, bem assim objetivos como liberdade, justiça, solidariedade, desenvolvimento, redução de desigualdades, promoção do bem comum ou coletivo e não discriminação compõe exatamente o rol de valores e princípios do cooperativismo, assim secularmente consagrados» ${ }^{23}$.

23 Meinen, Ênio. As sociedades cooperativas na Constituição Federal. In: Domingues, Jane Aparecida Stefanes (org.). Aspectos jurídicos do cooperativismo. Porto Alegre: Sagra Luzzatto, 2002, p. 26. 
Neste aspecto, encontra-se o vértice da cooperatividade em dispositivos peculiares da Carta Magna, quais sejam: o artigo $5 .^{\circ}, \mathrm{XVIII}$; o artigo 146, III, «C»; o artigo 174, § $2^{\circ}{ }^{\circ}, 3^{\circ}$ e $4 .^{\circ}$; o artigo 187, VI, 196, e 47, dos Atos e Disposições Constitucionais Transitórias ${ }^{24}$.

Inicialmente, no Título I, Capítulo I, dedicado aos Direitos e Deveres Individuais e Coletivos, o inciso XVIII, do artigo $5 .^{\circ}$, estabelece que «a criação de associações e, na forma da lei, a de cooperativas, independem de autorização, sendo vedada a interferência estatal em seu funcionamento ${ }^{25}$.

Posteriormente, no Título $\mathrm{VI}$, destinado ao Sistema Tributário Nacional, o artigo 146 é peremptório no sentido de que:

Cabe à Lei Complementar:

(...)

III - Estabelecer normas gerais em matéria de legislação tributária, especialmente sobre:

(..)

c) Adequado tratamento tributário ao ato cooperativo praticado pelas sociedades cooperativas. ${ }^{26}$

Ao longo do Título VII, que versa sobre a ordem econômica e financeira, e condensa os princípios gerais da atividade econômica, o artigo 174 aloca o Estado na condição de agente normativo e regulador da atividade econômica, devendo exercer "as funções de fiscalização, incentivo e planejamento, sendo este determinante para o setor público e indicativo para o setor privado» ${ }^{27}$. Sobre este aspecto, os parágrafos $2 .^{\circ}, 3 .^{\circ}$ e $4 .^{\circ}$, do artigo 174 , retratam a matéria cooperativa da seguinte forma:

$\S 2 .^{\circ}$ A lei apoiará e estimulará o cooperativismo e outras formas de associativismo.

$\S 3 .^{\circ}$ O Estado favorecerá a organização da atividade garimpeira em cooperativas, levando em conta a proteção do meio ambiente e a promoção econômico-social dos garimpeiros.

$\S 4 .^{\circ}$ As cooperativas a que se refere o parágrafo anterior terão prioridade na autorização ou concessão para pesquisa e lavra dos

24 Perius, Vergílio Frederico. Cooperativismo e lei. São Leopoldo, Unisinos, 2001.

25 Brasil, 1988. Constituição da República Federativa do Brasil, de 1988. Disponível em http://www.planalto.gov.br/ccivil_03/constituicao/constituicao.htm Acesso em 04 jan 2021.

26 Brasil, 1988.

27 Brasil, 1988. 
recursos e jazidas de minerais garimpáveis, nas áreas onde estejam atuando, e naquelas fixadas de acordo com o art. 21, XXV, na forma da lei..$^{28}$

Ainda dentro do Título VII, o Capítulo III, consagrado à Política Agrícola e Fundiária, e à Reforma Agrária, o artigo 187, determina que:

A política agrícola será planejada e executada na forma da lei, com a participação efetiva do setor de produção, envolvendo produtores e trabalhadores rurais, bem como dos setores de comercialização, de armazenamento e de transportes, levando em conta, especialmente:

(...)

VI. O cooperativismo. ${ }^{29}$

No Capítulo IV, que aborda o Sistema Financeiro Nacional, o artigo 192 dispõe que:

O sistema financeiro nacional, estruturado de forma a promover o desenvolvimento equilibrado do País e a servir aos interesses da coletividade, em todas as partes que o compõem, abrangendo as cooperativas de crédito, será regulado por leis complementares que disporão, inclusive, sobre a participação do capital estrangeiro nas instituições que o integram. ${ }^{30}$

Finalmente, nos Atos e Disposições Constitucionais Transitórias, o artigo 47 é categórico ao ajustar que «na liquidação dos débitos, inclusive suas renegociações e composições posteriores, ainda que ajuizados, decorrentes de quaisquer empréstimos concedidos por bancos e por instituições financeiras, não existirá correção monetária desde que o empréstimo tenha sido concedido» ${ }^{31}$. Sobre este aspecto, o parágrafo $7 .^{\circ}$ é definitivo ao assentar que «no caso de repasse a agentes financeiros oficiais ou cooperativas de crédito, o ônus recairá sobre a fonte de recursos originária» ${ }^{32}$.

\footnotetext{
28 Ibid.

29 Brasil, 1988.

30 Ibid.

31 Brasil, 1988.

32 Ibid.
} 


\section{Peculiaridades das cooperativas agropecuárias}

A partir da década de 70, o agronegócio brasileiro ingressou num processo de crescimento, perpassando pela superação de desafios estruturais e estratégicos, congêneres ao alcance de uma condição de sustentabilidade. De 1970, aos dias de hoje, o Brasil, de importador de alimentos, transformou-se num dos maiores exportadores globais de alimentos, energia e fibra.

«O forte dinamismo do agronegócio no país tem sido fundamental para mitigar os efeitos da crise, fortalecendo o desempenho da economia. Os superávits verificados na balança comercial nos últimos anos, se devem basicamente ao desempenho do agronegócio brasileiro e refletem a importância deste setor vis a vis a outros setores da economia. ${ }^{33}$ Ressalta-se, sobre este aspecto, que:

Visando a ampliação e modernização dos sistemas agroindustriais e o desenvolvimento de seus sistemas produtivos e de comercialização, as cooperativas agropecuárias cumprem seu papel participando de todos os elos das cadeias produtivas das principais matérias-primas e fibras. Neste sentido, contribuem ativamente para agregação de valor e o atendimento das necessidades de seus produtores cooperados no fornecimento de insumos, nas atividades de recepção, classificação, armazenagem, comercialização dos produtos agropecuários e no processamento dos produtos fornecidos por seus cooperados. ${ }^{34}$

Originariamente, as cooperativas agropecuárias eram caracterizadas essencialmente como cooperativas de produtores rurais ou pastoris e de pesca, cujos meios de produção pertencem ao cooperado. Prestavam, aos seus associados, serviços de recebimento ou comercialização da produção conjunta, armazenamento e industrialização, além da assistência técnica, educacional e social. Em vigília ao desenvolvimento econômico e social do Brasil, é capital assinalar que este ramo cooperativo, na medida em que foi se fortalecendo, assumiu uma considerável parcela de responsabilidade pelo aumento do Produto Interno Bruto do país.

Hodiernamente, a Organização das Cooperativas Brasileiras orienta que as cooperativas de produção agropecuária se destinam, essencialmente «a prover, por meio da mutualidade, o fomento relacionado às

33 OCB/BB. Cartilha de orientação às cooperativas agropecuárias. Disponível em https://www.somoscooperativismo.coop.br/publicacao/22/cartilha-de-orientacao-ascooperativas-agropecuarias Acesso em 04 jan 2021.

34 Ibid. 
atividades agropecuária, extrativista, agroindustrial, aquícola ou pesqueira. São formadas por produtores agrícolas, pecuários, pescadores e/ou extrativistas ${ }^{35}$.

A atuação das cooperativas agropecuárias é, na essência, bem variada, de forma que podem atuar para o fornecimento insumos, para a recepção e classificação de produtos, para a industrialização da produção, para a comercialização da produção, e, também, para a assistência técnica e produção rural.

Relevando-se a multiplicidade dos modelos de negócios que se encontram em «diversas cadeias produtivas de grãos, oleaginosas, fibras, carnes, lácteos e outras, são responsáveis pelas operações de fornecimento de insumos, classificação, armazenagem, processamento e comercialização dos produtos de seus associados, gerando economia de escala nos processos de compra e venda, promovendo a agregação de valor à produção e uma atuação menos assimétrica e mais concorrencial no mercado» ${ }^{36}$

Ao verificar a considerável expansão do Cooperativismo Agropecuário, o Sistema OCB subscreveu que:

O número de cooperativas e associados apresentou uma modesta alteração ao longo dos últimos anos. Quanto ao número de empregados houve um incremento significativo de $43,67 \%$ nos últimos 08 anos, resultado dos fortes investimentos e da ampliação da capacidade agroindustrial das cooperativas. O gasto total com despesas de pessoal em 2018 atingiu $R \$ 4,53$ bilhões.

Ao cumprirem as suas obrigações fiscais e tributárias, a exemplo da Contribuição Social sobre o Lucro Líquido (CSLL) e Imposto de Renda (IRPJ), assim como os demais tributos incidentes sobre as atividades econômicas (IPI, o ICMS, o PIS e a Cofins), as cooperativas contribuíram para arrecadação tributária para o financiamento da atividade estatal com o valor de aproximadamente $R \$ 5,13$ bilhões em $2018 .{ }^{37}$

Levando-se em consideração os efeitos que a pandemia do novo corona vírus iniciada no ano de 2020, provocou na economia global, e nacional, deve-se registrar o agronegócio brasileiro alça voos exemplares, pois, além de prosseguir abastecendo a mesa do consumidor interno, conforma um processo de exportação para mais de 170 países.

35 Sistema OCB, 2019. Anuário do Cooperativismo brasileiro. OCB, Brasília, 2019, p. 30 .

36 Ibid., p. 30.

37 Sistema OCB, 2019, p. 34. 
Entre os meses de janeiro a julho de 2020, o Brasil remeteu ao exterior 131,5 milhões de toneladas de produtos agrícolas, amealhando UD $\$ 61,2$ bilhões, 9,2\% a mais do que conseguira realizar no mesmo período, no ano de 2019. Coo decorrências deste resultado positivo, a perspectiva é de que a safra 2020/2021 permita a exportação de 278,7 milhões de toneladas.

Vista esta realidade, é necessário registrar que a participação do Cooperativismo agropecuário se revelou transcendental para o alcance dos indicadores positivos do agronegócio brasileiro. Salienta-se, portanto, que a representatividade numérica das cooperativas agropecuárias é bem considerável, pois, de acordo com os dados de 2020, do Anuário do Cooperativismo brasileiro, o Brasil conta com 1.223 cooperativas agropecuárias, 992.11 cooperados e 207.201 empregados $^{38}$.

A base organizacional do Cooperativismo Agropecuário brasileiro converge com o crescimento deste ramo cooperativo no mundo. Recorda-se, assim, que, de acordo com a Aliança Cooperativa Internacional, mais de $10 \%$ das 300 maiores cooperativas do mundo são do ramo agropecuário. Ademais, «in terms of cooperative type, almost half of the Top 300 are producer cooperatives (133 enterprises) mainly representing agricultural cooperatives and retailers' cooperatives» ${ }^{39}$

\section{Particularidades das cooperativas de consumo}

Impossível iniciar-se uma exposição das cooperativas de consumo brasileiras, sem o resgate de que este foi o ramo que deu origem ao Cooperativismo moderno, alicerçado sobre as bases da Cooperativa dos Probos Pioneiros de Rochdale, constituída no ano de 1844, em Manchester, na Inglaterra.

Na medida em que a prática dos Pioneiros de Rochdale se espaIhava pela Inglaterra, o modelo cooperativo de consumo tardou aproximadamente 50 anos para chegar ao Brasil. Somente no ano de 1889, através da criação da Cooperativa Econômica dos Funcionários Públicos de Ouro Preto, em Minas Gerais, os brasileiros passaram a conviver com a experiência do Cooperativismo de consumo. Posteriormente,

38 Disponível em http://sescooprn.coop.br/site/2020/12/acesse-o-anuario-do-cooperativismo-brasileiro-2020/ Acesso em 12 jan 2021.

$39 \mathrm{ACl}$, 2020. World Cooperative Monitor. Disponível em https://monitor.coop/en/ media/library/research-and-reviews/world-cooperative-monitor-2020 Acesso em 12 jan 2021. 
este modelo de cooperatividade expandiu-se para o resto do Brasil, sofrendo uma retração a partir de 1960, quando, além da supressão das isenções tributárias, as grandes redes de supermercado dominaram este setor da economia.

Sem fugir das características originárias, as cooperativas de consumo oferecem aos seus cooperados produtos de qualidade, com menor preço, atendimento diferenciado e segurança reconhecida. De um modo bem particular, verifica-se que:

Com a realização da compra em comum é possível reduzir os custos dos produtos, gerando economia refletida nos preços pagos pelos cooperados. Estas sociedades se classificam em dois tipos: fechadas ou abertas. As conhecidas como fechadas representam os cooperados ligados a uma empresa, sindicato ou profissão específicos. Já as abertas, ou populares, são as que permitem a associação de quaisquer pessoas interessadas, na condição de consumidores. ${ }^{40}$

Atualmente, as cooperativas de consumo brasileiras são identificadas como aquelas que se destinam, por meio da mutualidade, à compra em comum, de produtos e/ou serviços para seus cooperados. Estão representadas por supermercados, farmácias, convênios, postos de combustíveis, além das Cooperativas do Ramo Educacional, formadas por pais e alunos, e do Ramo Turismo e Lazer. «Em 2019 o setor supermercadista brasileiro, de acordo com as informações da Associação Brasileira de Supermercados (Abras), registrou 89.8 mil lojas em operação, atingindo a marca de $R \$ 378,3$ bilhões de faturamento, representando $5,2 \%$ do PIB e gerou mais de 1,8 milhão de empregos diretos. ${ }^{41}$

Por este caminho, salienta-se que o Cooperativismo de Consumo brasileiro apresenta consideráveis índices de desempenho, com destaque para os $R \$ 2,4$ bilhões de ativo total; $R \$ 803$ milhões de ativo imobilizado; $R \$ 1,1$ bilhão de patrimônio líquido; $R \$ 320,2$ milhões de capital social; $R \$ 69$ milhões de sobras de exercício; e, $R \$ 4,6$ bilhões de ingressos.

Vista a configuração das cooperativas de consumo, é necessário esclarecer que as Cooperativas do Ramo Educacional têm como objetivo à promoção de uma «educação de qualidade para a formação de cida-

40 Sistema OCB, 2014. Diagnóstico do ramo consumo. Disponível em https://www. somoscooperativismo.coop.br/publicacao/4/diagnostico-do-ramo-consumo\#. Acesso em 12 jan 2021.

41 Sistema OCESP, 2020. Raio X Cooperativismo: segmento varejo. OCESP, São Paulo, 2020, p. 6. 
dãos mais éticos e cooperativos e garantir um modelo de trabalho empreendedor para professores, e são formadas por professores, alunos, pais de alunos e pessoas apaixonadas por educação» ${ }^{42}$

De outra forma, as Cooperativas do Ramo Turismo e Lazer «prestam serviços de entretenimento para seus associados. De viagens a eventos artísticos e esportivos, esses empreendimentos oferecem opções mais baratas e educativas, além de contribuírem para que as comunidades explorem todo o seu potencial turístico» ${ }^{43}$.

Levando-se em conta os números levantados no ano de 2019, o Brasil conta com 263 cooperativas de consumo, que geram quatorze mil e oitocentos empregos, e agregam 2.025 milhões de cooperados. "Com o objetivo de abastecer seus cooperados fazendo compras em comum, essas instituições tornam os preços mais acessíveis além de manter a qualidade dos produtos ofertados. O ramo também é conhecido por sua diversidade, possuindo seis segmentos: serviços educacionais, produtos alimentícios, vestuário e beleza, supermercados farmácias e postos de combustíveis, serviços veiculares e turísticos e outros serviços. Cabe ressaltar a participação dos serviços educacionais, os quais representam $29 \%$ do setor, seguidos pelas cooperativas de produtos alimentícios, vestuário e beleza, as quais detém a parcela de $26 \% .{ }^{44}$

Não se pode deixar de elevar que um fator importante no sucesso das cooperativas de consumo brasileiras é a constante prática da intercooperação, levada a bom termo através da venda de produtos de cooperativas agropecuárias; parcerias diversas com o Ramo Crédito; desenvolvimento de novas formas de entrega junto ao Ramo Transporte. «A oferta de produtos com qualidade e preços mais acessíveis, bem como o acesso de mais pessoas a produtos e serviços que antes Ihes eram negados, seja por reservas injustificadas de mercado ou por preços altos, também está entre os benefícios trazidos pelas cooperativas do setor. Em 2019, o cooperativismo de consumo brasileiro devolveu aos cofres públicos do país $R \$ 330$ milhões 17 de reais em tributos. Isso sem contar os $\mathrm{R} \$ 486$ milhões alocados com salários e benefícios aos funcionários do ramo. ${ }^{45}$

Muito embora o cenário satisfatório das cooperativas de consumo brasileiros, o futuro reclama ponderação, e deixa em evidência que os principais desafios do ramo são:

$\begin{array}{ll}42 & \text { Ibid. } \\ 43 \text { Sistema OCESP, } 2020 . \\ 44 \text { Ibid. } \\ 45 \text { Sistema OCESP, } 2020 .\end{array}$ 
- Ausência de tratamento tributário adequado, tendo em vista a aplicação equivocada do entendimento de ato cooperativo às operações do ramo;

- Avanços regulatórios e legais. Acirramento da concorrência setorial.

- Dificuldades no financiamento das estruturas das cooperativas.

- A aplicação intensa de tecnologia no setor.

- O atendimento ao «novo consumidor/cooperado» que emergirá no pós-pandemia ${ }^{46}$.

\section{A nova estrutura do cooperativismo brasileiro}

A Organização das Cooperativas brasileiras iniciou, em 2018, um processo de estudos e reflexões sobre a organização dos ramos do Cooperativismo, até então estruturado sobre um alicerce de 13 segmentos, a saber: cooperativas agropecuárias; cooperativas de consumo; cooperativas de crédito; cooperativas educacionais; cooperativas habitacionais; cooperativas de infraestrutura; cooperativas de mineração; cooperativas de saúde; cooperativas de produção; cooperativas sociais; cooperativas de trabalho; cooperativas de transporte; cooperativas de turismo e lazer.

Com o propósito de otimizar uma melhor disposição, a ideia de «reorganização dos ramos levou em consideração a legislação societária e específica, a regulação própria, o regime tributário, o enquadramento sindical e a quantidade das cooperativas por ramo. Nossas quase sete mil cooperativas, agora, passam a integrar sete ramos» ${ }^{47}$.

O propósito, em si mesmo, buscava tento formar ramos fortes, com mais representatividade, como permitir que as entidades cooperativas se transformassem em organizações mais simples e flexíveis, capazes de se adaptarem às rápidas mudanças de mercado e inovação. Deste modo, a OCB editou a Resolução n. ${ }^{\circ}$ 56/2019, para regulamentar o processo de ressignificação e de fusão entre algumas cooperativas. Neste sentido, o Cooperativismo brasileiro passou a ter 07 ramos estruturados da seguinte forma:

- Cooperativismo agropecuário

- Cooperativismo de consumo

46 Ibid.

47 Sistema OCB, 2019. Ramos do Cooperativismo: conheça nossa nova organização. Brasília, OCB, 2019, 4. 
- Cooperativismo de crédito

- Cooperativismo de infraestrutura

- Cooperativismo de trabalho, produção de bens e serviços

- Cooperativismo de saúde

- Cooperativismo de transporte

Para não desprezar os modelos de cooperativas que integravam a configuração anterior, a atual organização permitiu que algumas cooperativas de outrora se fundissem dentro de um ramo específico, de forma que os ramos vigentes agregam as seguintes estruturas:

- Cooperativismo agropecuário, integrado, também, pelas cooperativas de alunos de escolas técnicas de produção rural

- Cooperativismo de consumo, absorveu as cooperativas de consumidores de turismo e lazer, e as cooperativas educacionais

- Cooperativismo de crédito

- Cooperativismo de infraestrutura, composto, igualmente, pelas cooperativas habitacionais

- Cooperativismo de trabalho, produção de bens e serviços, incorporado pelas antigas cooperativas de produção mineral, cooperativas de profissionais de turismo e lazer, cooperativas especiais e cooperativas de professores)

- Cooperativismo de saúde,

- Cooperativismo de transporte.

\section{Palavras derradeiras}

Já não mais se discute o fato de que, a partir do momento histórico em que surgiu, o Cooperativismo passou a representar um modelo de organização socioeconômica apropriada ao enfrentamento das múltiplas e intermináveis dificuldades que o homem enfrenta durante o seu transcuro pela passarela terrenal. Ressalta-se, assim, que «diante de situações turbulentas, o interesse pela comunidade se torna maior fazendo com que as pessoas se unam para enfrentar as dificuldades ${ }^{48}$.

Dentro do cenário brasileiro, a Organização das Cooperativas brasileiras não poupa sem empenho para consolidar a tenacidade da gestão democrática e contribuir para a constante adaptação dos processos internos, permitindo que o Cooperativismo nacional continue crescendo e contribuindo para o desenvolvimento da economia do Brasil e para o

48 Sistema OCESP, 2020. 
fortalecimento da condição humana de existir no mundo da vida. Não se pode, sob qualquer hipótese, esquecer-se que o empreendimento cooperativo é baseado em valores e princípios que enaltecem o valor do humano, com o propósito de fortalecer sempre a dignidade.

Perseguindo este vértice de orientação, o Cooperativismo brasileiro contribui para a melhoria de entornos debilitados, permitindo que pessoas alcem oportunidades que as conduzam pelos caminhos da realização pessoal e profissional. Enquanto ferramenta de desenvolvimento, o Cooperativismo é um modelo que não apenas deu certo, como serve de referência para a estruturação de novos empreendimentos socioeconômicos.

É necessário salientar que no ano de 2019, o ativo total do Cooperativismo brasileiro alcançou a marca de $R \$ 494$ bilhões, com um patrimônio líquido de $R \$ 126$ bilhões. "Essa tendência de crescimento é refletida no dia a dia de milhares de pessoas do país: nesse mesmo período nossas cooperativas injetaram nos cofres públicos mais de $\mathrm{R} \$ 11$ bilhões em tributos. ${ }^{49}$

Se o Brasil, hoje, cresce economicamente, passando a ocupar um espaço de referência no cenário internacional, o Cooperativismo, especialmente pelas cooperativas agropecuárias e de consumo, possui uma parcela considerável de responsabilidade por todas as mudanças positivas que o país vivenciou nas últimas décadas. Isto, sabidamente só foi possível porque o Cooperativismo aponta à supressão das necessidades do todo, e não à especulação, resulta do exercício coletivo, e não na individualidade. Por sua natureza axio-principiológica, o Cooperativismo associa o economicamente possível ao ecologicamente correto, e, sobretudo, ao socialmente justo.

É por isto que, para o Cooperativismo, o homem sempre será seu princípio e fim.

\section{Referências}

ACl, 2020. World Cooperative Monitor. Disponível em https://monitor.coop/ en/media/library/research-and-reviews/world-cooperative-monitor-2020 Acesso em 12 jan 2021.

BrASIL, 1903. Decreto $n .^{\circ}$ 979, de 6 de janeiro de 1903. Disponível em https:// www2.camara.leg.br/legin/fed/decret/1900-1909/decreto-979-6-janeiro1903 Acesso em 16 nov 2020.

49 Ibid. 
BrasiL, 1907. Decreto n. ${ }^{\circ}$ 1.637, de 05 de janeiro de 2907. Disponível em https://www2.camara.leg.br/legin/fed/decret/1900-1909/decreto-1637-5janeiro-1907-582195-publicacaooriginal-104950-pl.html Acesso em 17 nov 2020

BRASIL, 1932. Decreto n. $^{\circ} 22.239$, de 19 de dezembro de 1922. Disponível em https://www2.camara.leg.br/legin/fed/decret/1930-1939/decreto-2223919-dezembro-1932-501764-publicacaooriginal-1-. Acesso em 17 nov 2020.

BRASIL, 1933. Decreto 23.611, de 20 de dezembro de 1933. Disponível em http://www.planalto.gov.br/ccivil_03/decreto/antigos/d23611.htm Acesso em 17 nov 2020.

BRASIL, 1934. Decreto 24.647, de 10 de julho de 1934. Disponível em http://www.planalto.gov.br/ccivil_03/decreto/1930-1949/D24647. htm\#: :text=DECRETO\%20N\%C2\%BA\%2024.647\%2C\%20DE\% 20 $10 \% 20$ DE \% 20JULHO \% 20DE \% $201934 . \&$ text $=22.239 \% 2$ C \% 20 de $\% 2019 \% 20$ de $\% 20$ dezembro,Patrim \% C 3\% B 4nio \% 20dos \% 20 Cons\%C3\%B3rcios\%20Profissionais\%2DCooperativos. Acesso em 17 nov 2020.

BrASIL, 1938. Decreto 581, de 1 de agosto de 1938. Disponível em http:// www.planalto.gov.br/ccivil_03/Decreto-Lei/1937-1946/Del581.htm Acesso em 28 nov 2020.

BRASIL, 1943. Decreto 5.893, de 19 de outubro de 1943. Disponível em http:// www.planalto.gov.br/ccivil_03/Atos/del/1943/Del05893.htm . Acesso em 17 nov 2020.

BrASIL, 1951. Lei 1.412. de 13 de agosto de 1951. Disponível em http://www. planalto.gov.br/ccivil_03/leis/1950-1969/1412.htm . Acesso em 12 dez 2020.

BrASIL, 1971. Lei 5.764, de 16 de dezembro de 1971. Disponível em http:// www.planalto.gov.br/ccivil_03/leis//5764.htm Acesso em 17 dez 2020.

Brasil, 1988. Constituição da República Federativa do Brasil, de 1988. Disponível em http://www.planalto.gov.br/ccivil_03/constituicao/constituicao.htm Acesso em 04 jan 2021.

BrASIL, 1999. Lei 9.867, de 10 de novembro de 1999. Disponível em http:// www.planalto.gov.br/ccivil_03/leis/L9867.htm Acesso em 17 dez 2020.

BrASIL, 2002. Lei 10.406, de 10 de janeiro. Disponível em http://www.planalto. gov.br/ccivil_03/leis/2002/L10406compilada.htm Acesso em 22 dez 2020.

BRASIL, 2009. Lei complementar 130, de 17 de novembro de 2009. Disponível em http://www.planalto.gov.br/ccivil_03/leis/LCP/Lcp130.htm Acesso em 17 dez 2020.

BrasiL, 2012. Lei 12.690, de 9 de julho de 2012. Disponível em http://www. planalto.gov.br/ccivil_03/_Ato2011-2014/2012/Lei/L12690.htm Acesso em 17 dez 2020.

MeInen, Ênio. As sociedades cooperativas na Constituição Federal. In: Domingues, Jane Aparecida Stefanes (org.). Aspectos jurídicos do cooperativismo. Porto Alegre: Sagra Luzzatto, 2002. 
OCB/BB. Cartilha de orientação às cooperativas agropecuárias. Disponível em https://www.somoscooperativismo.coop.br/publicacao/22/cartilha-deorientacao-as-cooperativas-agropecuarias Acesso em 04 jan 2021.

Perius, Vergílio Frederico. Cooperativismo e lei. São Leopoldo, Unisinos, 2001.

SISTEMA OCB, 2019. Anuário do Cooperativismo brasileiro. OCB, Brasília, 2019

SISTEMA OCB, 2014. Diagnóstico do ramo consumo. Disponível em https:// www.somoscooperativismo.coop.br/publicacao/4/diagnostico-do-ramoconsumo\#. Acesso em 12 jan 2021.

SISTEMA OCB, 2019. Anuário do Cooperativismo brasileiro. OCB, Brasília, 2019.

SISTEMA OCB, 2019. Ramos do Cooperativismo: conheça nossa nova organização. Brasília, OCB, 2019.

SISTEMA OCESP, 2020. Raio X Cooperativismo: segmento varejo. OCESP, São Paulo, 2020.

Sistema OCB, 2020. Anuário do Cooperativismo brasileiro. OCB, Brasília, 2020. 


\section{Derechos de autor}

http://dec.revistas.deusto.es/

La revista Deusto Estudios Cooperativos es una revista de acceso abierto lo que significa que es de libre acceso en su integridad inmediatamente después de la publicación de cada número. Se permite su lectura, la búsqueda, descarga, distribución y reutilización legal en cualquier tipo de soporte sólo para fines no comerciales y según lo previsto por la ley; sin la previa autorización de la Editorial (Universidad de Deusto) o el autor, siempre que la obra original sea debidamente citada (número, año, páginas y DOI si procede) y cualquier cambio en el original esté claramente indicado.

\section{Copyright}

The Deusto Journal of Cooperative Studies is an Open Access journal which means that it is free for full and immediate access, reading, search, download, distribution, and lawful reuse in any medium only for non-commercial purposes, without prior permission from the Publisher or the author; provided the original work is properly cited and any changes to the original are clearly indicated. 